\title{
La bóveda anular del Palacio de Carlos V en Granada. Hipótesis constructiva
}

\section{The Annular Vault of Carlos V Palace in Granada. Constructive Hypothesis}

B. Líndez ${ }^{(*)}$, M. Rodríguez ${ }^{(*)}$

\section{RESUMEN}

La bóveda anular de perfil carpanel del cortile del palacio de Carlos V es un sistema estructural mecánicamente autoestable una vez finalizada la construcción. De tal modo que los empujes hacia el exterior se equilibran por el peso de la masa construida perimetralmente, mientras que los empujes hacia el interior, son absorbidos por un anillo de dovelas que conforma un arco plano apoyado sobre columnas, en el que actúa un sistema de fuerzas de resultante nula. Por el contrario, durante el proceso constructivo la estructura es inestable. Dada la complejidad constructiva, resulta aún más intrigante desentrañar cuál pudo ser el proceso de ejecución, tanto por la excelencia en la factura estereométrica como por la perfección geométrica lograda. Con este trabajo proponemos una hipótesis para el procedimiento constructivo que se ajuste al principio de economía de medios, orden racional de los trabajos, seguridad del proceso y excelencia de resultados.

Palabras clave: Bóveda anular; autoestable; arco plano; construcción; equilibrio.

\section{ABSTRACT}

The annular vault with basket-handle profile in the cortile of Carlos V palace is a self-stable structural system once the construction is finished. The forces to the exterior are absorbed by the weight of the perimetral masses, while the efforts to the interior are absorbed by a ring of voussoirs that forms a flat arch supported by columns, constituting a force system whose resultant is zero. Nevertheless, during the construction process the structure is unstable. Given the constructive complexity, it becomes even more intriguing to figure out which the execution process could be, both for the excellence of the stereometric construction and for the geometrical perfection reached. With this work we propose an hypothesis for the construction procedure that adjusts to the principle of the economy of means, rational order of the work, security of the process and excellence of results.

Keywords: Annular vault; self-stable; flat arch; construction; equilibrium.

(*) Universidad de Granada (España).

Persona de contacto/Corresponding author: blindez@ugr.es (B. Líndez)

Cómo citar este artículo/Citation: Líndez, B., Rodríguez, M. (2015). La bóveda anular del Palacio de Carlos V en Granada. Hipótesis constructiva. Informes de la Construcción, 67(540): e125, doi: http://dx.doi.org/10.3989/ic.15.004.

Licencia / License: Salvo indicación contraria, todos los contenidos de la edición electrónica de Informes de la Construcción se distribuyen bajo una licencia de uso y distribución Creative Commons Reconocimiento no Comercial 3.o. España (cc-by-nc). 


\section{INTRODUCCIÓN}

Tras la conquista del reino de Granada, la Alhambra representa un documento fedatario para la historia de primerísimo orden, razón por la que el interés de la corona se centra en la apropiación y redefinición urbana del recinto áulico con la construcción de tres hitos arquitectónicos: Puerta de las Granadas, Pilar y Palacio de Carlos V (1).

En este contexto el Palacio Imperial persigue la ostentación de valores universales en sus aspectos formales: cuadrado en la envolvente de la planta y círculo en el patio interior, estableciendo relaciones de linaje con el Imperio Romano al adoptar el modelo toroidal del Teatro Marítimo de Villa Adriana en Tívoli (Roma), con referencias de aquilatada excelencia arquitectónica, como el Tempietto de San Pietro in Montorio de Bramante, en el diseño del patio circular del palacio granadino (2).

La iniciativa parte de D. Iñigo López de Mendoza, primer conde de Tendilla, militar y diplomático que ostenta las mayores cotas de poder en el aparato burocrático del Estado. Personaje entre lo medieval y lo renacentista, en cuya compleja personalidad se advierte no sólo un amplio prurito humanista, sino también una notable sensibilidad hacia los moriscos en lo social y cultural (3). Buena prueba de ello es el auténtico mimo con que cuida y conserva la Alhambra en el ejercicio de su cargo como alcaide perpetuo, que hará hereditario en su familia.

El proyecto se encarga a Pedro Machuca, pintor y escultor prestigiado por su estancia en Italia, cuya formación se desarrolla a la sombra de Miguel Ángel y en el entorno del círculo bramantiano de arquitectos como Giulio Romano, Sanmichelli, Sansovino o Baldasare Peruzzi (4) y que, al amparo del régimen jurídico especial de la Alhambra, escapará al control gremial dominante en la ciudad.

El primero de los tres hitos arquitectónicos construidos, la Puerta de las Granadas, delimita la ciudad palatina y se articula a partir de una disposición triunfal de triple vano. El segundo, el Pilar de Carlos V, financiado a expensas del Conde de Tendilla, elabora el campo adecuado donde materialidad y referencias iconográficas proponen la difusión de los intereses propagandísticos de la corte, iniciando un discurso alegórico/simbólico en torno a la imagen del Emperador que se completa en el Palacio.

\section{EL PALACIO DE CARLOS V}

La probada insuficiencia espacial de la Casa Real Vieja, hacía necesaria la construcción de una Casa Real Nueva, concebida en términos funcionales como ampliación de la primera, aunque serán razones de carácter político y moral las responsables del diseño arquitectónico, en aras al reforzamiento de la figura del monarca frente a sus súbditos en el contexto nacional y del Emperador en el universal. Esta segunda faceta, la imperial, será la que se manifieste de forma ostensible en las trazas y referencias iconográficas del palacio (5).

La impronta y rotundidad de formas y volúmenes del diseño arquitectónico, su escala referencial, así como la ubicación precisa entre los dos palacios nazaríes mejor conservados, ejercen el deseado impacto visual en la redefinición y apropiación simbólica del conjunto alhambreño conforme a los nuevos presupuestos ideológicos (Figura 1).

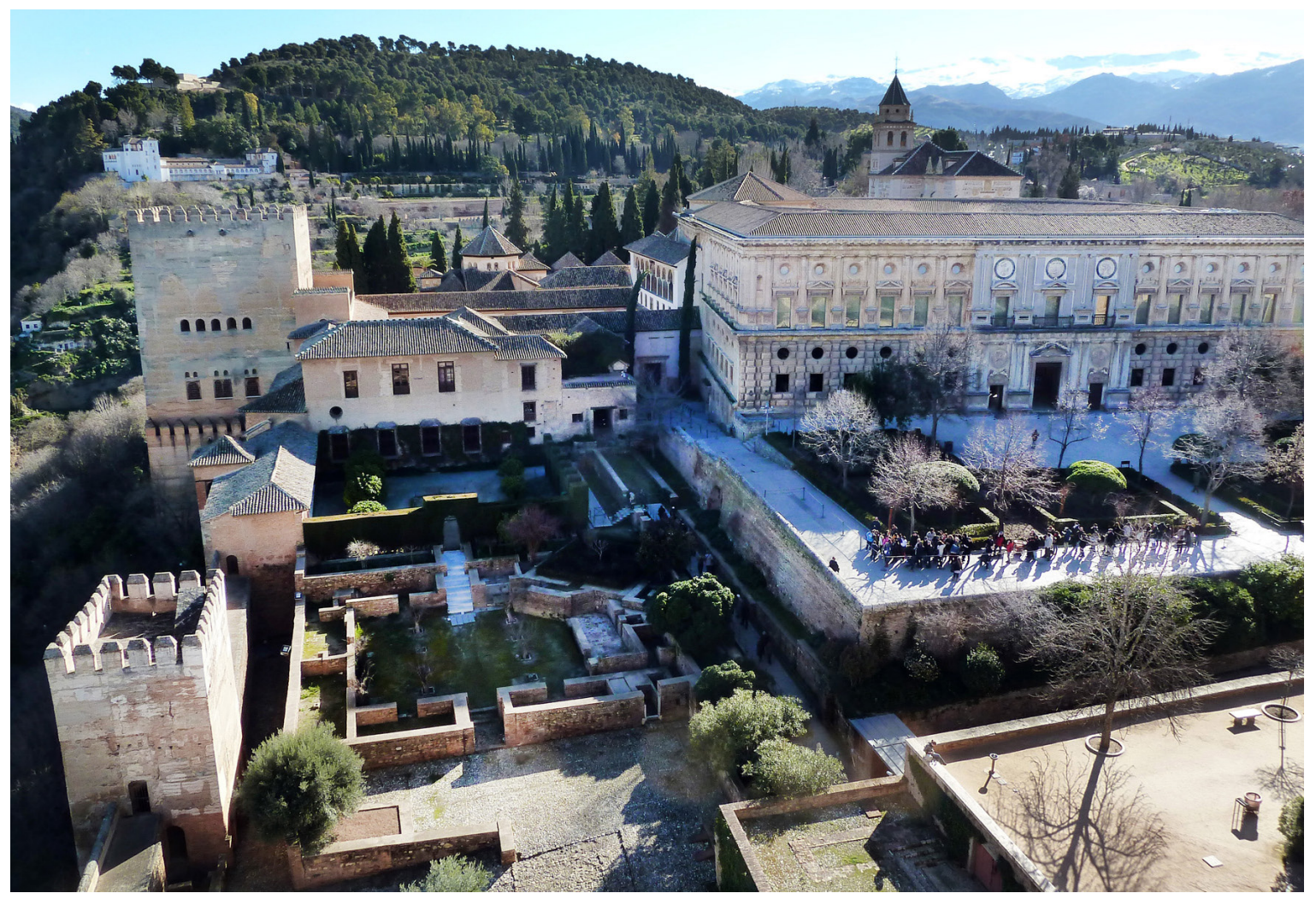

Figura 1. Vista general del palacio de Carlos V y su inserción en el conjunto alhambreño. (Fotografía de los autores). 
La geometría de la planta (Figura 2), basada en la utilización del cuadrado y el círculo como formas puras generadoras del espacio, se corresponde con la idea de perfección formal e ideal que hunde sus raíces en tradiciones religiosas hindúes y judías, que más tarde recoge el clasicismo en su concepción neoplatónica asociando al círculo y al cuadrado, como figuras perfectas, la idea de lo eterno y absoluto en representación misma de la bóveda celeste (6), frente a lo humano, delimitado por los ejes de los cuatro puntos cardinales. Macrocosmos y microcosmos, lo divino y lo terrenal, junto al octógono de la capilla como figura de transición y vínculo religioso entre ambas concepciones, constituye una propuesta simbólica al servicio de la idea renacentista de la autoridad imperial.

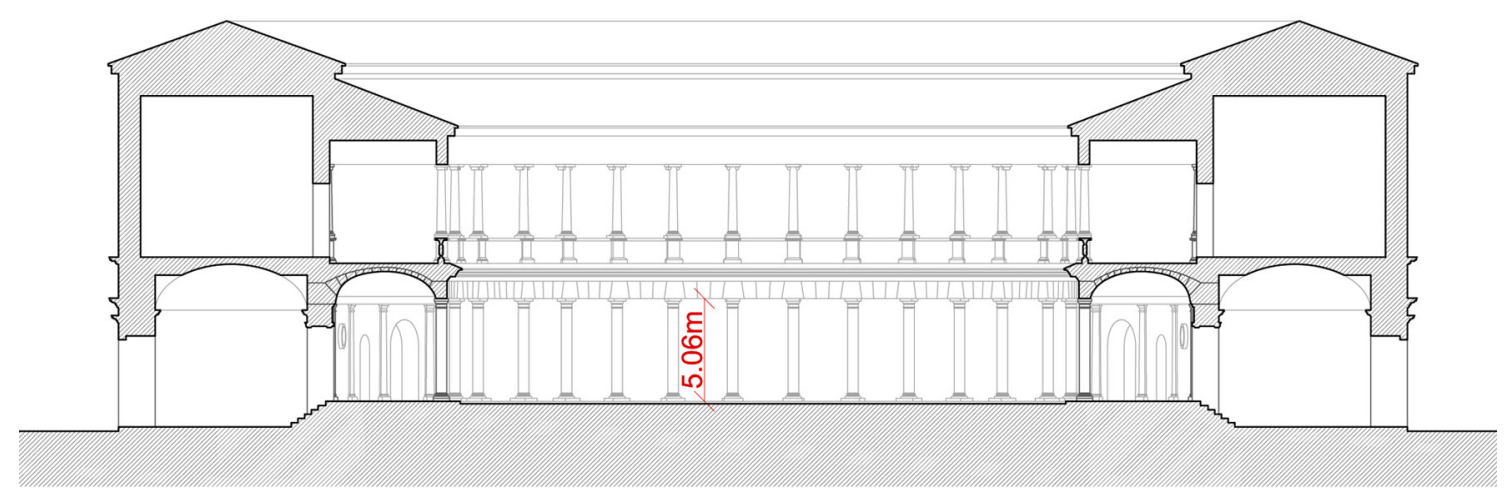

$63.28 \mathrm{~m}$

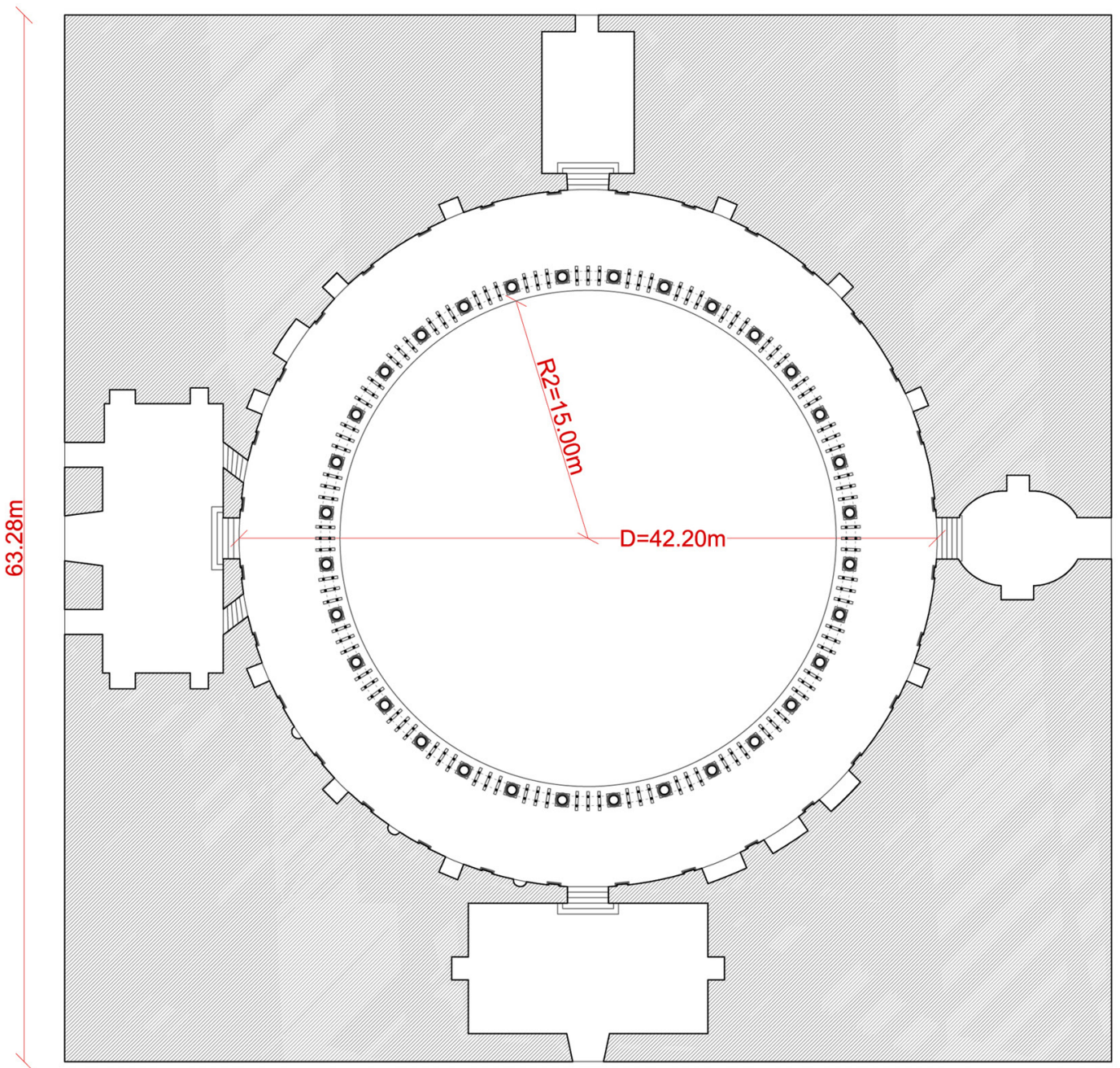

Figura 2. Planta y sección del palacio. En la planta esquemática se representan únicamente los zaguanes y el patio con la disposición de columnas que apean la bóveda anular. La sección corta los zaguanes occidental y oriental, adviértase la diferencia de cota entre el patio y los accesos. (Elaboración propia). 
La distribución interior reserva las alas norte y oeste al Emperador y la sur y este a la Emperatriz, prevaleciendo en el diseño la geometría y escala de los zaguanes de acceso frente al resto de dependencias, salvo el octógono de la capilla, confinado en el ángulo nor-oriental y accesible visualmente desde los aposentos de ambos cónyuges por expreso deseo del emperador (7).

La originalidad de la planta, sin antecedentes claros en la arquitectura palatina italiana del cuatrocientos, en la que Manfredo Tafuri quiere ver la mano de Giulio Romano como auténtico tracista y a Pedro Machuca como su autor material (8), presenta un paralelismo claro en el diseño del patio circular tanto con el Teatro Marítimo de la Villa Adriana en Tívoli, como con el Tempietto de San Pietro in Montorio de Bramante (Figura 3).

Los alzados exteriores, auténticos protagonistas del diseño arquitectónico por su enorme fuerza expresiva, materializan de manera excepcional la imagen de firmeza, robustez, grandeza, majestad, triunfo y magnificencia del monarca. Las portadas reservadas al emperador y la emperatriz en los lados oeste y sur, recurrirán en sus diseños tanto a la metáfora clásica como al relato histórico. Encajadas en la fábrica de sillería ligeramente resaltadas, delatan proyectos posteriores que se imponen al primero.

En cuanto al emplazamiento, como analiza Antón Capitel (9), el tracista demuestra su sensibilidad y respeto al monumento nazarí, manteniendo las cuatro fachadas que formalmente definen el palacio de Comares, consciente del valor que le confiere la integridad. Renuncia a las panorámicas que el monumento nazarí ofrecería al palacio renacentista en su lienzo norte, pero se asienta físicamente sobre el anterior en la sala de las Aleyas, haciendo visible la imposición sobre el primero. El único eje de simetría del palacio imperial, la diagonal en el ángulo de la capilla, se inserta como bisectriz de los dos ejes principales de los palacios nazaríes (Comares y Leones), materializando la apropiación simbólica de ambos. Arquitectónicamente, el octógono de la capilla actúa como rótula y bisagra en la articulación volumétrica resultante, facilitando el diálogo entre los palacios nazaríes y el nuevo palacio renacentista. Ejercicio brillante de composición arquitectónica que, junto a las referencias simbólicas de la planta ya mencionadas, evidencia el profundo conocimiento del conjunto alhambreño por parte del autor de las trazas del nuevo palacio.

Se completa así el discurso alegórico/simbólico en que la arquitectura, en su ejercicio propagandístico, sirve de manera magistral los intereses de la corte como traducción plástica y figurativa de las virtudes y valores morales reconocibles en los héroes míticos con los que pretende enraizarse la monarquía española. La figura de Carlos V, como emperador de la cristiandad y auténtico garante de la estabilidad en el Mediterráneo, tiene en el palacio granadino uno de los mejores ejemplos de pureza arquitectónica del clasicismo español. Por otro lado, ejemplifica de manera excepcional el difícil problema compositivo y de articulación arquitectónica del producto de dos culturas de altísima cualidad estética, evidenciando figurativamente su contraste, manifiesto desde las múltiples panorámicas que ofrece su emplazamiento, pero a la vez enfatizando los fuertes vínculos que las unen por sus similitudes, no sólo desde el punto de vista formal, sino por su ascendencia común, la arquitectura clásica.

\section{JUSTIFICACIÓN Y OBJETIVOS}

La abundante historiografía en torno al Palacio de Carlos V ha puesto de manifiesto la excelencia arquitectónica del proyecto, cuestionando la autoría de Pedro Machuca a favor de arquitectos italianos como Giulio Romano o Baldasare Peruzzi. Se alimenta el debate a partir de aspectos filológicos en torno al lenguaje utilizado ante la falta documental o la existencia de trazas contemporáneas como la Planta Grande (1528-29), la Planta Pequeña (1529) o el plano conservado en Toledo, A.H.N. (1528?) atribuido por Rosenthal a Luis de Vega y por Tafuri y Marías a Siloé (10).

Del mismo modo se enfatiza la cualidad de las obras de fábrica, sobre todo la impecable ejecución de la bóveda esquifada de ocho plementos con lunetos de la cripta de la capilla terminada en 1542 (11) y el toroide que cierra la galería inferior del patio. Este último concluido con anterioridad a 1570, probablemente bajo la dirección de Luis Machuca, cuya dificultad constructiva se pone de manifiesto en el informe de Juan de
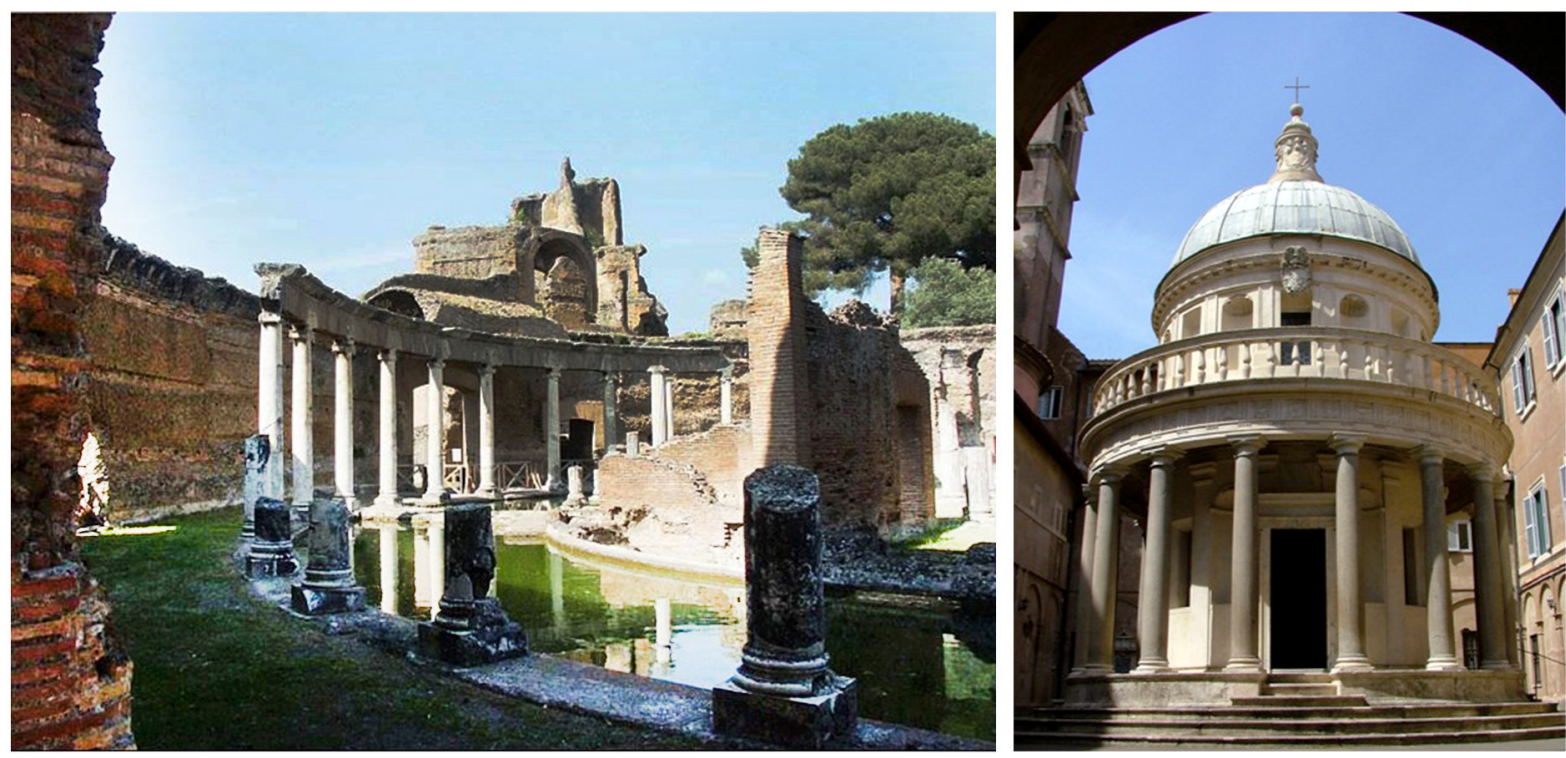

Figura 3. Teatro Marítimo de la Villa Adriana en Tívoli y Tempietto de San Pietro in Montorio. (Fotografías de los autores). 
Maeda de 1576 que duda de la capacidad estructural del soporte en los tres puntos débiles donde están proyectadas las escaleras (12). Efectivamente, las construcciones de fábrica en piedra suelen presentar, por lo general, problemas de estabilidad y no de resistencia, siendo el factor crítico la forma de la estructura del conjunto, adecuada en este caso, aunque de insuficiente masa en los ángulos donde estaban proyectadas las escaleras como oportunamente advierte Maeda.

Alonso de Vandelvira expone la dificultad constructiva de este tipo de bóveda en patio redondo con columnas - «Mas este patio aquí abaxo mostrado aunque con columnas es algo más dificultoso...»-, complejidad que Maeda subraya al recomendar para la ejecución de una pieza así el parecer y la maestría de Rodrigo Gil de Hontañón o de Andrés de Vandelvira (13).

Chueca Goitia se refiere a ella como «estructura interesantísima» en la que «no cabe mayor perfección técnica ni mayor inteligencia estructural». Concluye aludiendo a la forma tórica que elude los contrafuertes y la apunta como una posible razón en la adopción del patio circular «que permitía a la vez el abovedamiento pétreo y el sistema adintelado, tan ligero» (14).

Para Galera Andreu «la construcción de la bóveda anular del corredor, es otro de los grandes alardes técnicos que ofrece el monumento por la limpieza y perfección con que se encastra en el muro y descansa sobre las columnas» (15), pero en ningún caso se describe el proceso constructivo, cuya complejidad se hace visible por la enorme esbeltez del anillo interior y por la forma del intradós de la bóveda de perfil carpanel por tranquil asimétrico, que entraña un gran problema de geometría descriptiva en la labra de las dovelas.

Resulta extraño que ni Rosenthal ni Tafuri hagan referencia al toroide que cierra la capilla Junterón en la catedral de Murcia (1525-1543), atribuida a Jacopo Torni (el Florentino), aunque realizada probablemente por Jerónimo Quijano, escultor español, tras la muerte de Torni 10 meses después de iniciadas las obras (16). La presencia del Florentino en Granada trabajando en las obras de la cabecera de San Jerónimo o en el retablo de la Santa Cruz en la Capilla Real, da pistas en torno a la posible influencia del arquitecto italiano en el pensamiento arquitectónico de Machuca. Hay evidentes paralelismos entre el toroide de la capilla Junterón y el que cierra la galería inferior del palacio granadino, sin embargo geométricamente el primero es un toroide de revolución en torno a un eje horizontal, frente al del palacio de Carlos V que gira en torno a un eje vertical. Quizá esa sea la razón por la que Alonso de Vandelvira se refiere a él con el apelativo tan singular de «bóveda de Murcia».

Desvelar cuál pudo ser la solución constructiva adoptada en la ejecución de la bóveda granadina es el objeto de este trabajo, que abre de nuevo el debate en torno a la autoría de la bóveda y del proyecto del palacio en su conjunto. La solución definitivamente realizada es la que mejor sirve los intereses ideológicos de la corona y por tanto nos remite a la idea primigenia del proyecto imperial, a pesar de la alusión de Maeda en su informe al plano conservado en el A.H.N. (Toledo) - «aver movido la sustancia y traza del modelo porque era primero con sus columnas acompañadas por los lados con los pies derechos y movimientos sobre que se cerraban los arcos redondos...»-. Lo ejecutado entraña una mayor dificultad constructiva que evidencia la maestría de los canteros españoles en la traza y corte de la piedra y en el dominio de sistemas de equilibrio.

\section{LA BÓVEDA ANULAR DEL PATIO, HIPÓTESIS CONSTRUCTIVA}

Como antecedente directo, el Teatro Marítimo de Villa Adriana se compone a partir de una rotonda muraria de $42 \mathrm{~m}$ de diámetro y un pórtico anular concéntrico de 40 columnas de orden jónico, cerrado por un toroide de sección semicircular. La plementería de hormigón romano formaliza la bóveda de medio punto, apoyada sobre un arco plano de ladrillo que apea sobre una gran dovela de piedra dispuesta en el eje de las columnas. Sobre éste, una almohadilla de piedra rematada en cornisa y lastrada con un pequeño peto de ladrillo. El estado fragmentario y de ruina en que se encuentra en la actualidad demuestra la estabilidad de la solución estructural, en la que los arcos planos de ladrillo (sin carga por haberse desplomado la bóveda) se comportan ahora como dinteles, trabajando a flexión con la simple adherencia del mortero, que les confiere un cierto monolitismo. La lámina de hormigón que conforma la plementería de la bóveda anular, ejerce un empuje hacia el anillo interior de resultante nula gracias a la geometría toroidal.

El mayor número de columnas en Villa Adriana, 40 frente a 32 en el palacio granadino, hace que el intercolumnio sea casi un metro mayor en éste. Si consideramos como unidad de medida el pie en sus dimensiones más comunes (pie 29,5 cm, palma 7,5 cm y el dedo $2 \mathrm{~cm}$, aunque Rosenthal sugiere el pie castellano de 27,5 cm) (17), las dimensiones del diámetro del patio son 100 pies en la cara interior de las basas de columnas. Como el número de columnas son 32 , arroja un intercolumnio redondeando de 10 pies (las basas miden $84 \times 84 \mathrm{~cm}$ y el diámetro inferior del fuste de las columnas es de $64 \mathrm{~cm}$ ). Medidas razonables, sobre todo estas últimas que debían ser exactas para la labra de las dovelas del arco plano que formaliza la circunferencia interna.

La bóveda anular que circunvala el patio (Figura 4), materializada en piedra calcarenita bioclástica de las canteras de Santa Pudia en el término de Escúzar, (Granada), obra perfecta de cantería de perfil carpanel por tranquil muy rebajado (135 cm de flecha frente a $495 \mathrm{~cm}$ de luz) sin contrafuertes en uno de sus apoyos, es sin duda una de las principales fábricas de cantería del renacimiento español y el mayor logro estructural del proyecto.

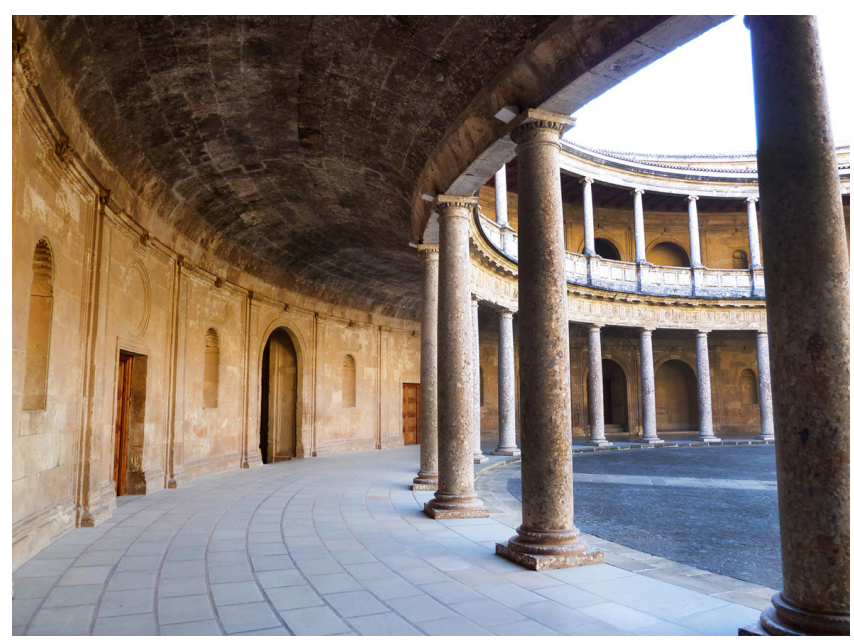

Figura 4. Bóveda anular del Palacio de Carlos V, apeada

perimetralmente en el muro y en el anillo interior, formado por arco plano que se apoya en un pórtico de columnas dórico-toscanas. (Fotografía de los autores). 
Realizada en la segunda mitad del siglo XVI con una soberbia estereotomía, absorbe sus empujes en el muro perimetral y en el anillo circular conformado por el entablamento plano dovelado (Figura 5), ligeramente lastrado por el peto de pro- tección del piso alto, sin necesidad de contrafuertes. El doble pórtico de columnas, toscanas en el nivel inferior y jónicas sobre pedestales en el nivel superior, completan la fachada interior del cortile.

patio
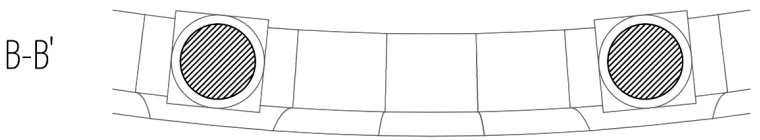

bóveda
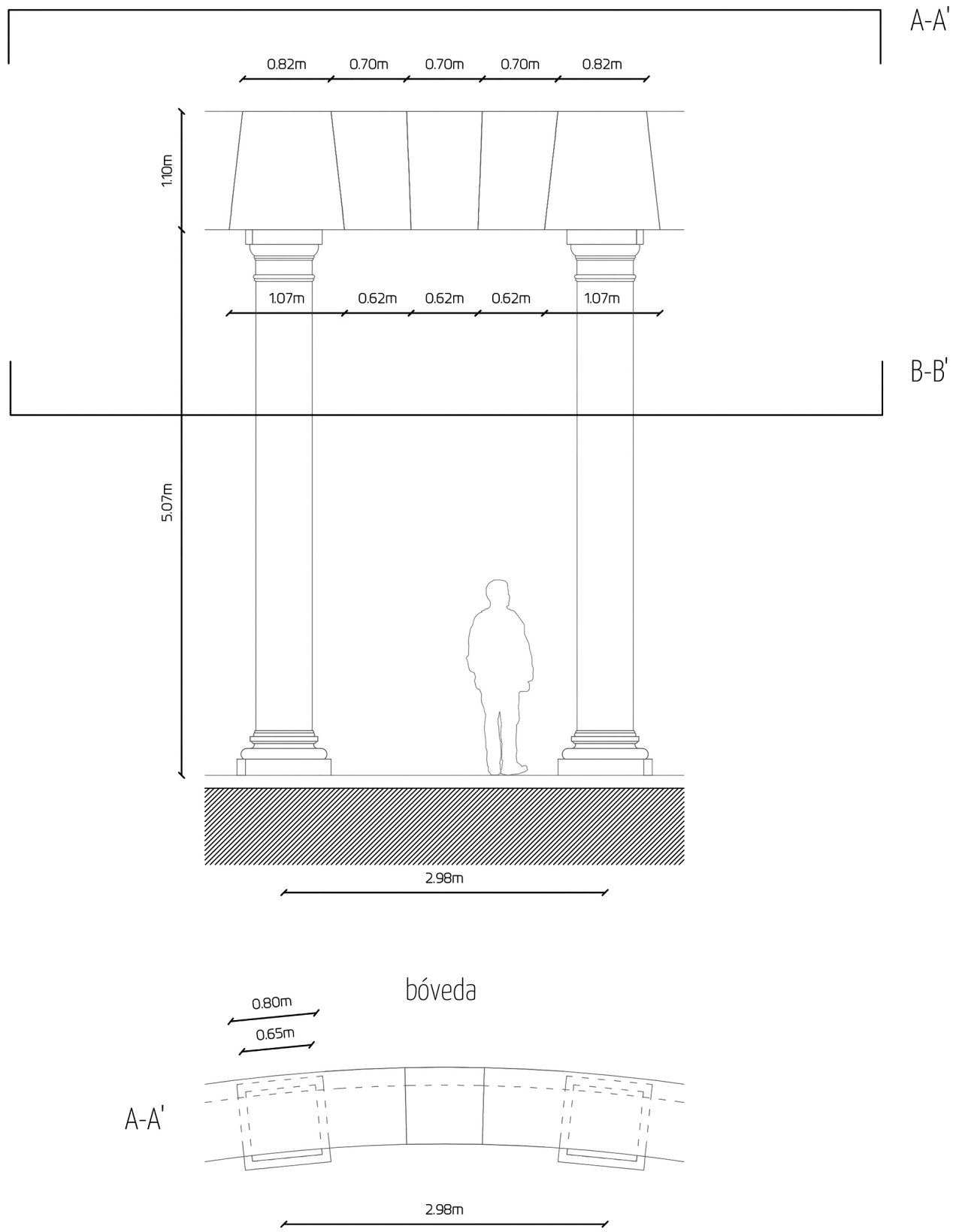

patio

Figura 5. Planta y alzado del pórtico que contiene el arco plano en el anillo interior. (Elaboración propia). 
Su construcción debió de resultar revolucionaria para los arquitectos de la época, todos ellos de formación gótica, expertos en la estereotomía de la piedra y en el dominio de sistemas de equilibrio basados en cálculos gráficos, a partir del uso de bóvedas nervadas apeadas mediante contrafuertes y arbotantes. Sin embargo, la bóveda anular resulta una forma extraña a la tradición constructiva medieval española.

La solución adoptada, es responsable en buena medida de la pureza arquitectónica (en sentido bramantiano) que ofrece, sirviéndose como contrapunto epidérmico de la piedra almendrilla de las canteras del Turro (18) en la búsqueda y logro de los valores plásticos y estéticos perseguidos (Figura 6).

Ya se ha explicado el interés del proyecto imperial granadino en la adopción del círculo para el patio, en base a los valores universales que le atribuye la filosofía neoplatónica, y con el objeto de establecer relaciones de linaje de Carlos V con el más grande de los emperadores de Roma de ascendencia hispana, el emperador Adriano. De ahí la adopción como modelo del teatro marítimo de Villa Adriana en Tívoli, a lo que ha de sumarse la excepcional belleza y elegancia formal de la solución arquitectónica en la cualificación del espacio, capaz de alimentar la fantasía creadora del arquitecto español, como intérprete de aquél en clave de modernidad.

El ejemplo más cercano, el castillo de Bellver, construido en Mallorca en el siglo XIV, presenta una doble galería claustral de planta circular resuelta con tramos trapezoidales de bóvedas de crucería en el piso alto, cuyo comportamiento mecánico y proceso constructivo resulta mucho más intuitivo y que, en todo caso, a nosotros nos puede servir también como ejemplo, ya que en el castillo gótico habrá de realizarse primero el anillo interior de arcos formeros superpuestos entrelazados y más tarde los arcos que dibujan tramos trapezoidales, apeados en las columnas del anillo interior y que se entregan en el muro perimetral junto a los nervios diagonales. Estructura ósea que precomprime el anillo interior y soporta las cimbras para la ejecución de los plementos (Figura 7).

El piso inferior está resuelto con alfarje plano y el piso superior con bóveda de crucería. Adviértase que en el anillo interior se doblan los arcos formeros y se apuntalan con dos nervios más que apean sobre una columna central que actúa como parteluz. Se genera así una línea imaginaria (línea roja) que actúa como arco plano y absorbe la componente horizontal que transmiten los nervios diagonales de la bóveda de crucería.

La construcción en Tívoli no debió representar reto alguno para el genio de Roma, inmersos en ese momento como estaban en la construcción de la cúpula del Panteón. Probablemente ya en el siglo XVI el estado de conservación de la fábrica del teatro marítimo, permitiría la lectura de la materialidad de la obra, así como la toma de medidas exactas de su geometría. Del mismo modo, al mantenerse en pie fragmentos de la bóveda anular y del pórtico de arcos planos del anillo interior, sin el concurso de contrafuerte alguno, se evidencia la especial aptitud de la forma toroidal en la obtención del equilibrio. Hemos de observar que el uso del hormigón romano tanto para mortero en la construcción de arcos planos, como en la conformación de la plementería de la bóveda, permite minimizar las secciones y sobre todo es capaz de asumir esfuerzos de flexión, aunque de forma limitada. Aquí suponemos que construido el anillo interior a base de arcos planos de ladrillo, se realizase una cimbra anular de toda la bóveda que permitiría el hormigonado en una sola fase, provocando la precompresión, de manera uniforme, conforme se producía el hormigonado, desde los riñones hasta la clave de la bóveda.

Volviendo de nuevo al Palacio de Carlos V, sabemos que la bóveda anular de perfil carpanel por tranquil, es un sistema estructural mecánicamente autoestable una vez finalizada la construcción. De tal modo que los empujes hacia el exterior son absorbidos por el peso de la masa construida perimetralmente, mientras que los empujes hacia el interior se equilibran dentro del anillo de dovelas que conforman el arco plano apoyado sobre columnas, en el que actúa un sistema de fuerzas de resultante nula. Por el contrario, durante el proceso constructivo la estructura es inestable. Dada la complejidad constructiva (19), resulta aún más intrigante desentrañar cuál pudo ser el proceso de ejecución, tanto por la excelencia en la factura estereométrica como por la perfección geométrica lograda.

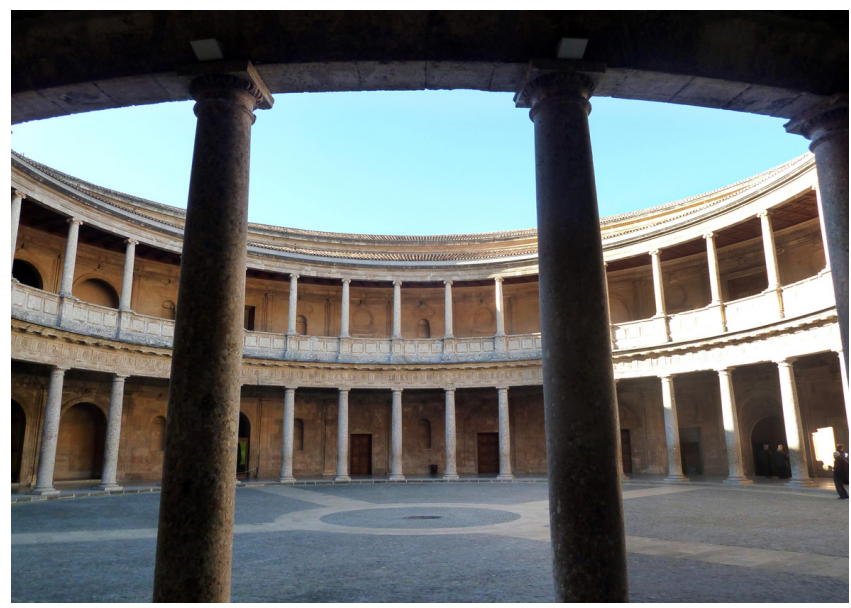

Figura 6. Patio circular del Palacio de Carlos V, articulando un doble pórtico de columnas dórico toscanas en el piso inferior y jónicas en el piso superior. (Fotografía de los autores).

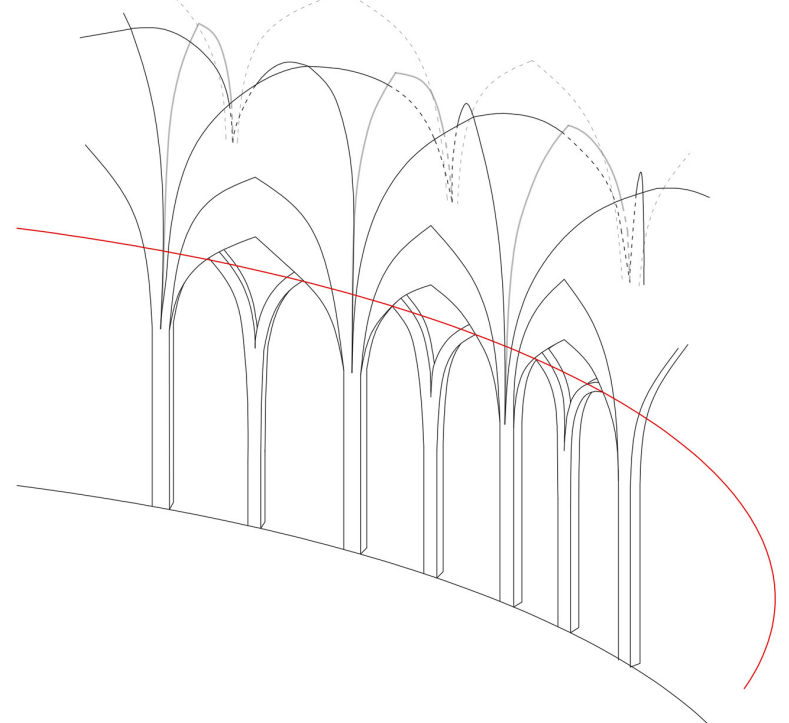

Figura 7. Esquema estructural de la solución gótica del castillo de Bellver en Palma de Mallorca. (Elaboración propia). 
Mediante simple inspección ocular, se advierte claramente que en el lado del muro, la primera dovela forma parte de la fábrica de éste y se ejecuta previamente. De igual forma, el anillo interior que conforma el arco plano se ofrece también como primera dovela de un total de 15 que pueden contarse en la sección de la bóveda anular.

Resueltos los dos puntos de apoyo, la construcción del toroide con dovelas de piedra requiere el concurso de cimbra, y tratándose de una geometría compleja, con recursos limitados y siguiendo la tradición medieval, habría de realizarse por tramos deslizando la cimbra. Se puede observar lo que podrían ser juntas de dovelaje en 4 puntos equidistantes del toroide, lo que sugiere la ejecución por tramos independientes en cuatro tajos. Pero esto entraña un problema derivado de la gran esbeltez del anillo interno, ya que al descimbrar y entrar en carga cualquier tramo del toroide, provocaría una deformación del anillo interior y probablemente su desestabilización.

Llegados a este punto parece razonable que si el esfuerzo resultante de un tramo descimbrado de bóveda desequilibraría el anillo interior en razón de su esbeltez, se aplicase desde el interior del patio y con directriz radial una fuerza equivalente que anulase aquella. Sin embargo, esto sólo aumentaría los problemas estructurales, ya que aplicada esta fuerza en el intradós del anillo, acabaría descomprimiéndolo y por tanto desestabilizándolo. A ello habría que sumar el impedimento físico al acopio y desplazamiento de materiales y de personas dentro de la obra, unido a la construcción de andamios necesarios para la labra de triglifos y metopas en la formalización del entablamento definido en el intradós del arco plano, que necesariamente debió de realizarse in situ, ya que éstos ocupan a veces el campo de dos dovelas, con el requerimiento de andamios que comporta y la especialización de los distintos tajos de trabajo (Figura 8).

Dada la perfecta geometría de la fábrica toroidal ejecutada, y teniendo en cuenta razones estructurales, constructivas, económicas y organizativas, volvemos nuevamente a formularnos la pregunta: Cómo pudo realizarse la bóveda anular de cantería con resultados geométricos y estereométricos perfectos. La respuesta la encontramos en el proverbio árabe «el arco, que nunca
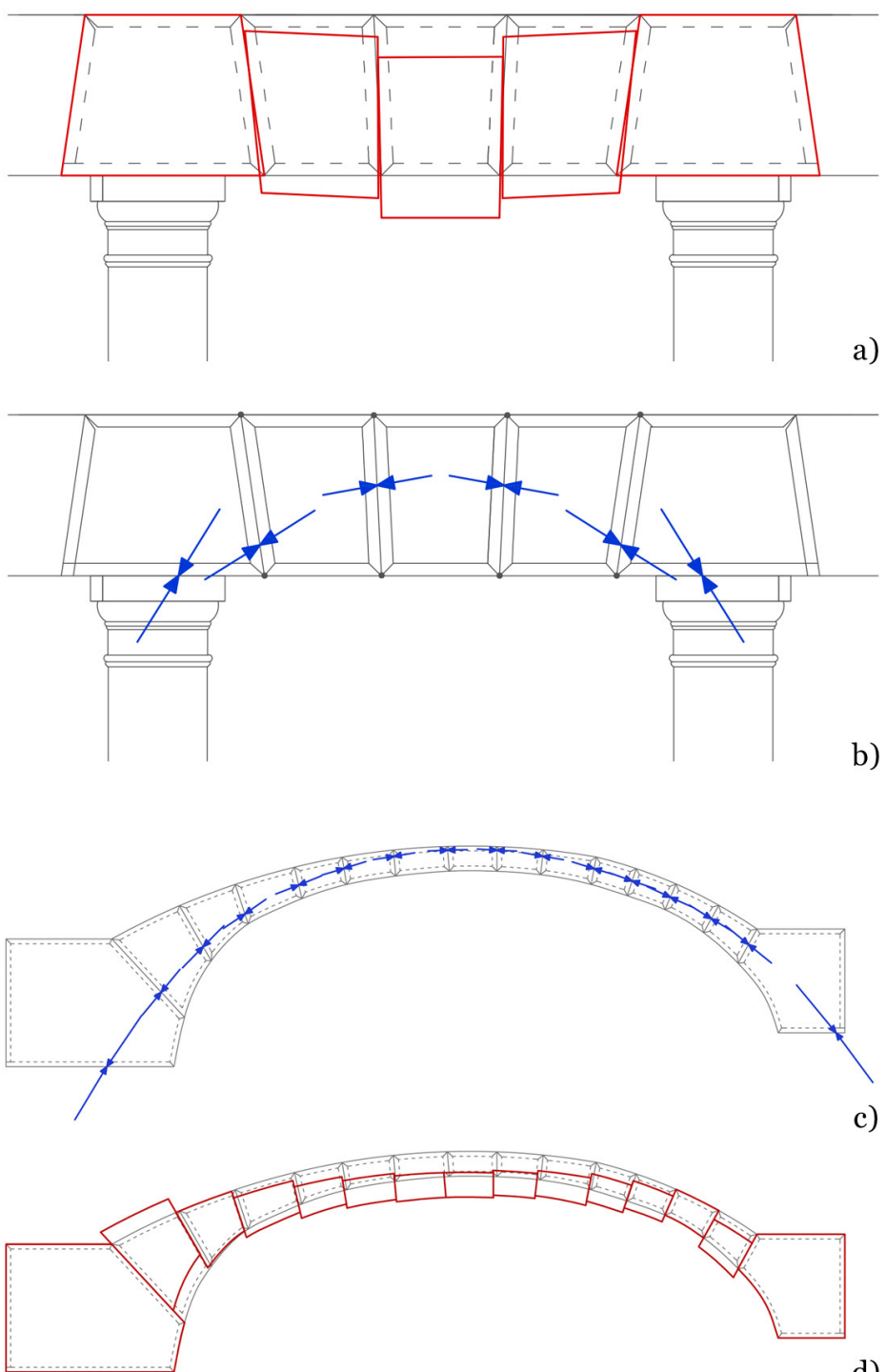

c)

Figura 8. Esquema del comportamiento estructural del arco plano que conforma el anillo interior (a, b) y de la bóveda anular (c, d). (Elaboración propia). 

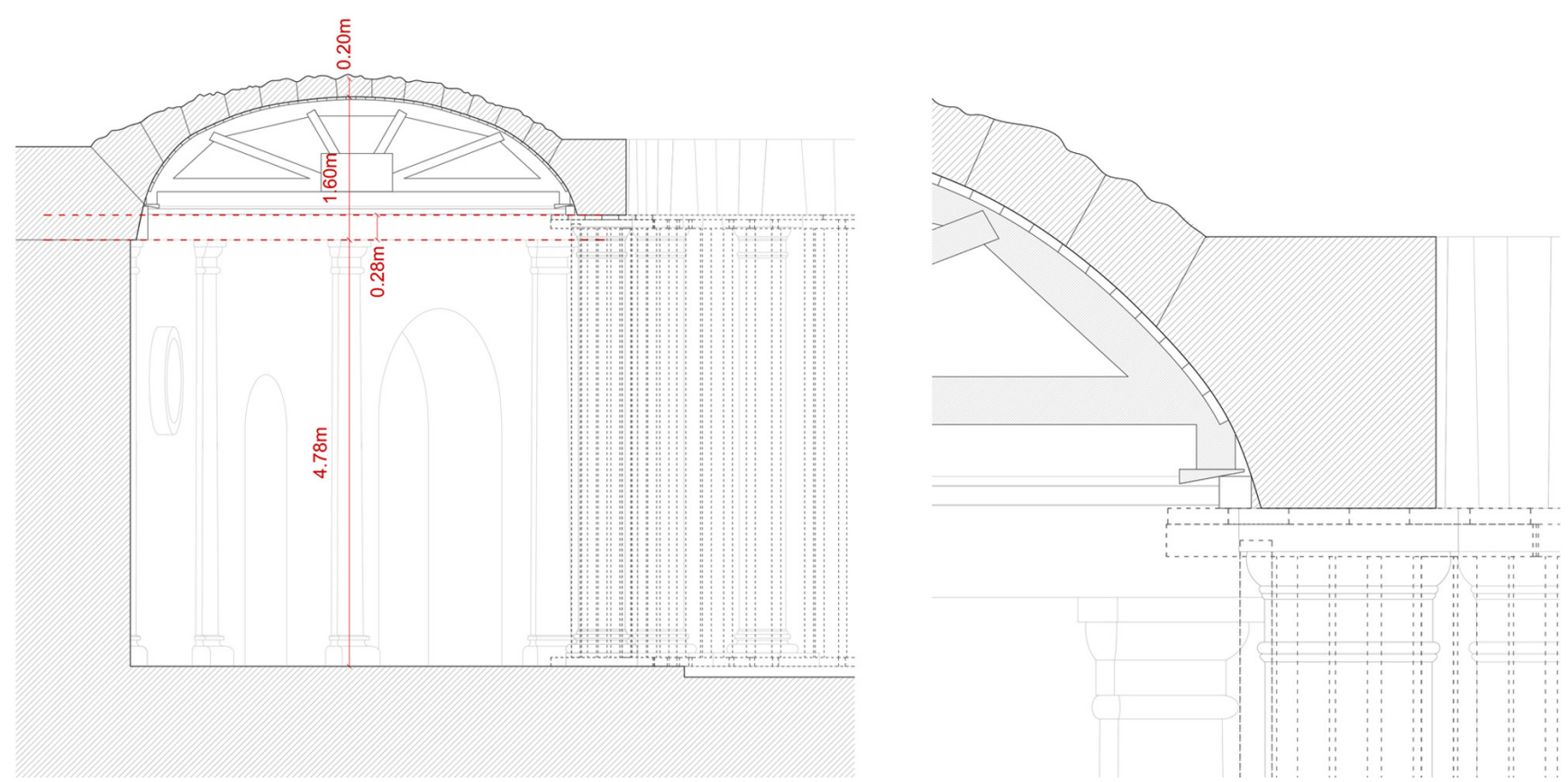

Figura 9. Sección del toroide cimbrado y detalle del apoyo de la cimbra. (Elaboración propia).

duerme», en alusión a la aptitud del arco a mantener su integridad soportando esfuerzos de compresión que lo hacen más estable. Ahí está la «clave» que resuelve nuestro problema: habría de realizarse la pre-compresión uniforme del total del anillo interior, a partir de la cual una cimbra deslizante giraría a través de unas guías hasta la total conclusión del mismo (Figura 9).

Es decir, se realizaría el muro perimetral exterior hasta la altura de la cubierta para tener la suficiente masa que actúe como lastre, dejando el arranque de la primera dovela. Las pilastras adosadas al muro adoptan capiteles con ábacos en voladizo que dibujan un plano horizontal perfecto. Replanteo y elevación de las columnas que conforman el anillo interior. Cimbrado del arco plano realizado en la totalidad del anillo, abrazando el ábaco de los capiteles de las columnas toscanas en el plano superior de éstos. Dovelado del arco plano con lo que se obtiene la primera dovela de la bóveda anular en el lado del patio. Esta operación requiere un gran conocimiento de geometría descriptiva, pero si se realiza un perfecto replanteo de las columnas, bastaría con diseñar la plantilla de cuatro dovelas y repetir la operación 32 veces.

Dado que hay que precomprimir uniformemente el arco plano para obtener mayor estabilidad (eliminando el riesgo de colapso por pandeo o por flexión), bastaría con colocar sendas cerchas horizontales de madera que circunvalen la totalidad de la circunferencia, sobre el plano que dibujan los ábacos de las pilastras en el cerramiento exterior y sobre el de las columnas en el anillo interno, acodalando radialmente éstas con puntales de madera a intervalos coincidentes con los ejes de las columnas y con los intercolumnios e imprimiéndoles una mínima tensión. Se obtienen así las guías (cerchas horizontales de madera) sobre las cuales giraría la cimbra con el perfil de la bóveda, procediendo al acuñamiento de ésta para elevarla unos centímetros y así permitir el descimbrado posterior en la ejecución por tramos de la totalidad de la bóveda toroidal, lo que justifica una única junta de dovelaje que representa el inicio y final de la misma.
Esta junta de dovelaje está perfectamente visible en el lado norte del zaguán oriental (Figura 10). Las otras tres, mucho más delgadas, coinciden con puntos débiles de la estructura envolvente, probablemente fruto de ligeras deformaciones de ésta, magnificadas ante nuestros ojos por torpes intervenciones restauradoras.

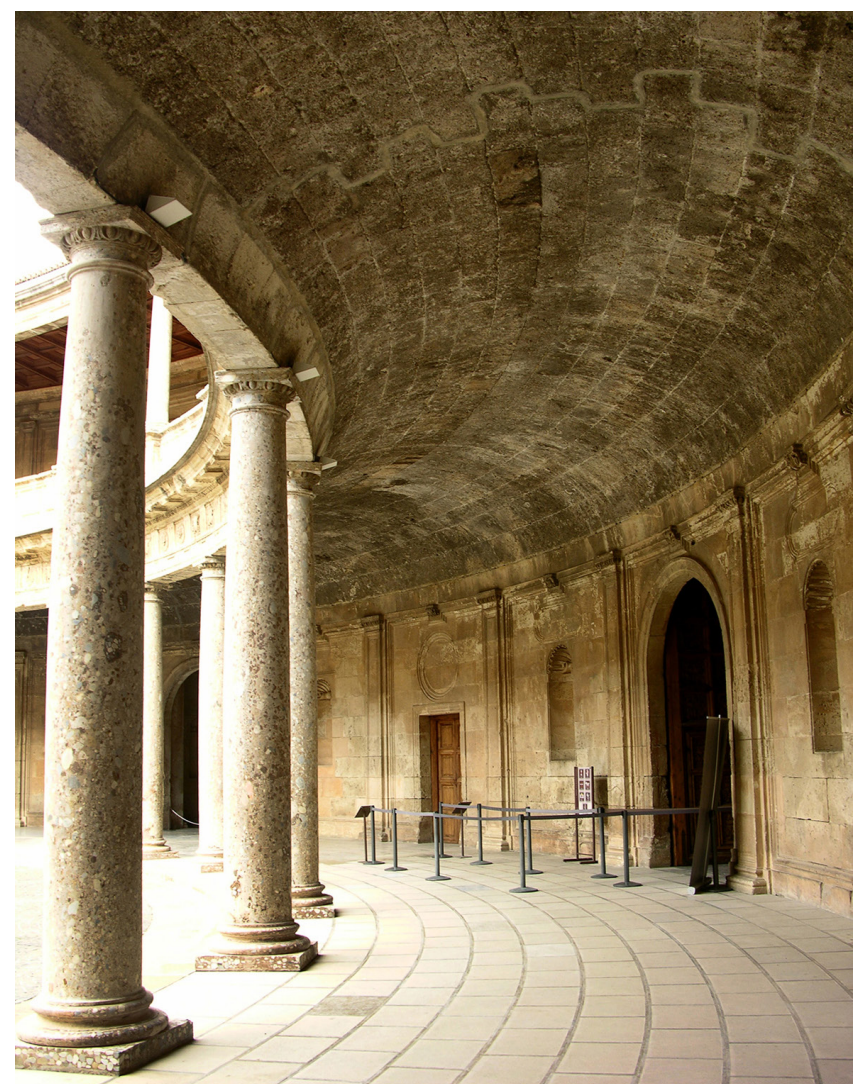

Figura 10. Vista interior del toroide en la que se puede apreciar la junta de inicio y final del dovelado de la bóveda. (Fotografía de los autores). 
Descartado el apuntalamiento radial desde el interior del patio, y aceptada la pre-compresión del anillo interior antes del inicio de la construcción de la bóveda anular, basta una observación superficial del toroide, para intuir el proceso constructivo y sobre todo, para advertir los detalles que han posibilitado la excelencia en la ejecución de una de las fábricas de cantería de mayor solvencia del renacimiento español (Figura 11).
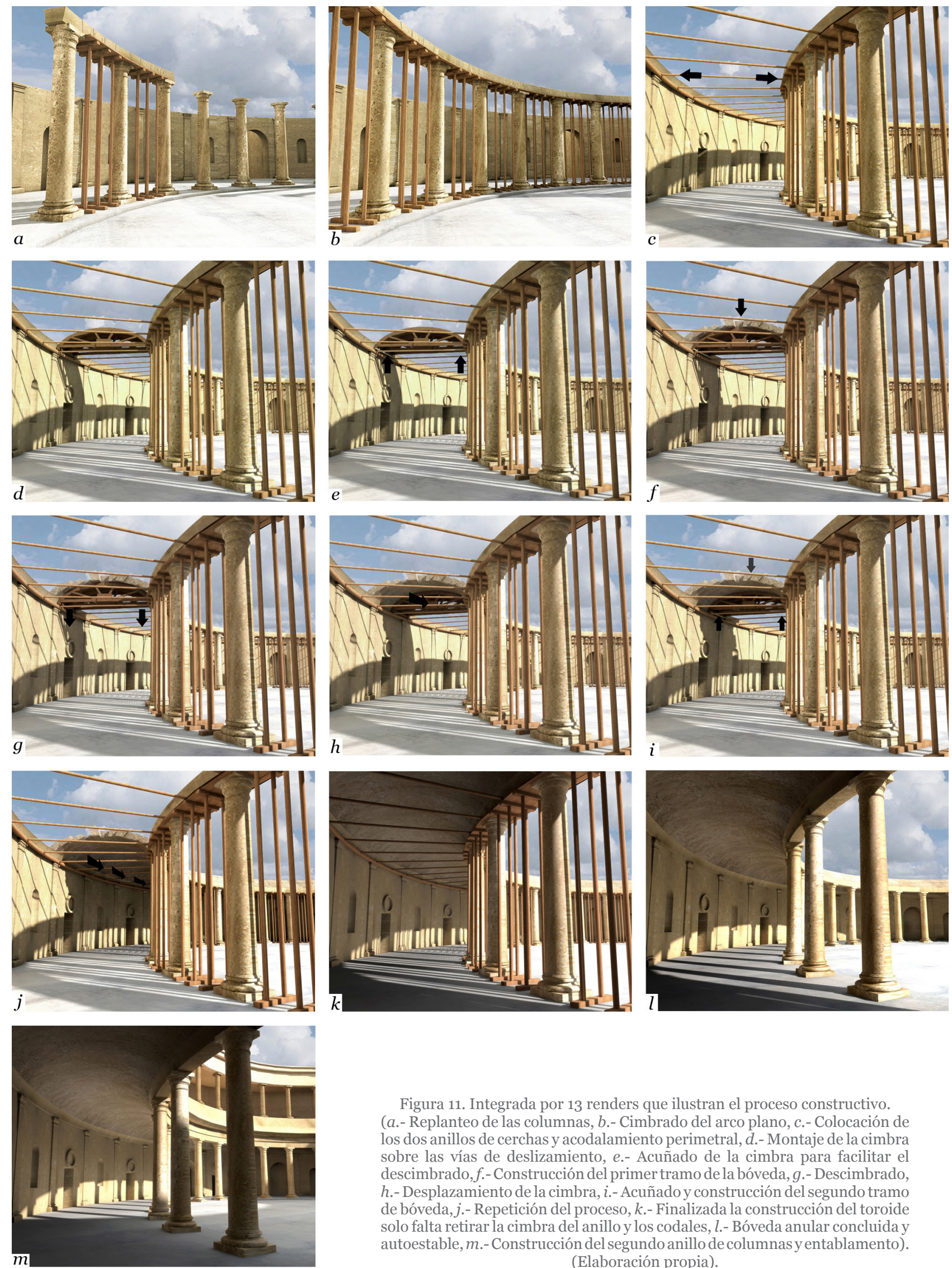

Figura 11. Integrada por 13 renders que ilustran el proceso constructivo. (a.- Replanteo de las columnas, $b$.- Cimbrado del arco plano, c.- Colocación de los dos anillos de cerchas y acodalamiento perimetral, $d$.- Montaje de la cimbra sobre las vías de deslizamiento, e.- Acuñado de la cimbra para facilitar el descimbrado, $f$ - Construcción del primer tramo de la bóveda, $g$.- Descimbrado, $h$.- Desplazamiento de la cimbra, $i$.- Acuñado y construcción del segundo tramo de bóveda, $j$.- Repetición del proceso, $k$.- Finalizada la construcción del toroide solo falta retirar la cimbra del anillo y los codales, l.- Bóveda anular concluida y autoestable, $m$.- Construcción del segundo anillo de columnas y entablamento). (Elaboración propia). 


\subsection{El supuesto constructivo. Las distintas etapas para la ejecución de la bóveda toroidal}

A partir de este supuesto, proponemos el siguiente orden de los trabajos de construcción de la bóveda, conforme a las ilustraciones gráficas que siguen:

1. Construcción de la fábrica de sillería envolvente hasta la altura de la primera dovela integrada en ésta.

2. Construcción del anillo de 32 columnas interiores.

Ha de hacerse notar que la disposición de las columnas coincide en intercolumnios ortogonales con los ejes de los cuatro zaguanes y que se proyectan radialmente en el muro en órdenes de pilastras. El ábaco de éstas y de las columnas dibuja el plano en el que se apoyarán las cerchas curvas sobre las que deslizará la cimbra (ilustración $a$ ).

3. Construcción y apeo de una cimbra anular plana que abrace el ábaco de las columnas a la altura del plano superior de éste. Esta cimbra ha de realizarse para todo el anillo, ya que los empujes horizontales del arco plano volcarían la columna contigua, por lo que debe mantenerse apeada al menos hasta la pre-compresión del anillo (ilustración $b$ ).

4. Construcción del anillo interior que conforma el arco plano y que se convierte en la primera dovela del toroide (ilustración $b$ ).

5. Disposición de sendas cerchas de madera, de escuadría constante, en todo el anillo a ambos lados sobre los ábacos de las columnas y pilastras. Paralelamente se irán situando codales haciéndolos coincidir con los ejes de columnas e intercolumnios, mediante los cuales se aplicará una mínima tensión sobre el anillo interior que se transmitirá de manera uniforme a éste a través de las cerchas, quedando así pre-comprimido con una tensión uniforme de resultante nula (ilustración $c$ ).

6. Se colocará la cimbra de madera con la forma anular en tramos similares al intercolumnio, calzada con cuñas sobre la cercha varios para facilitar después el descimbrado. (Figura 9) (ilustraciones $d$ y $e$ ).

7. Ejecución del tramo de plementería (ilustración $f$ ).
8. Descimbrado, (sacando las cuñas la cimbra desciende sobre la cercha varios centímetros liberándose del peso muerto del tramo de bóveda ejecutado) y deslizado de la cimbra a través de las cerchas guías, para la ejecución del tramo siguiente, manteniendo un pequeño solape con el tramo anterior. En este punto se traslada al anillo interior el empuje del tramo de bóveda descimbrado que será absorbido por los codales que apuntalan el zuncho perimetral del arco plano evitando posibles deformaciones (ilustración $g$ ).

9. A partir de aquí se repetirán los puntos 6,7 y 8 hasta la total conclusión (ilustraciones $h, i, j$ ).

10. Descimbrado y eliminación de apeos, cerchas y codales (ilustraciones $k, l$ ).

11. Construcción del peto y pórtico superior de columnas jónicas, que introduce el peso que contribuye a un sistema de equilibrio autoestable (ilustración $m$ ).

Hemos de insistir en dos aspectos que consideramos esenciales para la correcta ejecución y la obtención de una geometría perfecta en el toroide. En primer lugar, un riguroso replanteo de las columnas del anillo interno y de las pilastras del muro envolvente dispuestas radialmente. En segundo lugar, la contribución de las columnas y pilastras como plano de apoyo por separado de las cerchas de madera, de sección constante, que han de servir de vías de sostén y deslizamiento de la cimbra toroidal.

La amplia curvatura del arco plano con diámetro a ejes de columnas de 30,5 m, frente al intercolumnio de $3 \mathrm{~m}$, hace que cada uno de los tramos sea prácticamente una banda recta, lo que permite el descimbrado antes de la construcción del toroide, obligándolo así a entrar en carga y por tanto asumiendo las mínimas deformaciones que provoca el acomodo del dovelaje de éste por su peso propio (20).

La geometría del intradós de la bóveda, con apoyos a alturas desiguales, y sobre todo con un trazado asimétrico de aparente perfil carpanel, dibuja una elipse en el lado del patio que contiene la directriz del esfuerzo resultante sin necesidad de lastre en los riñones, lo que hace aún más estable la bóveda (Figura 12).

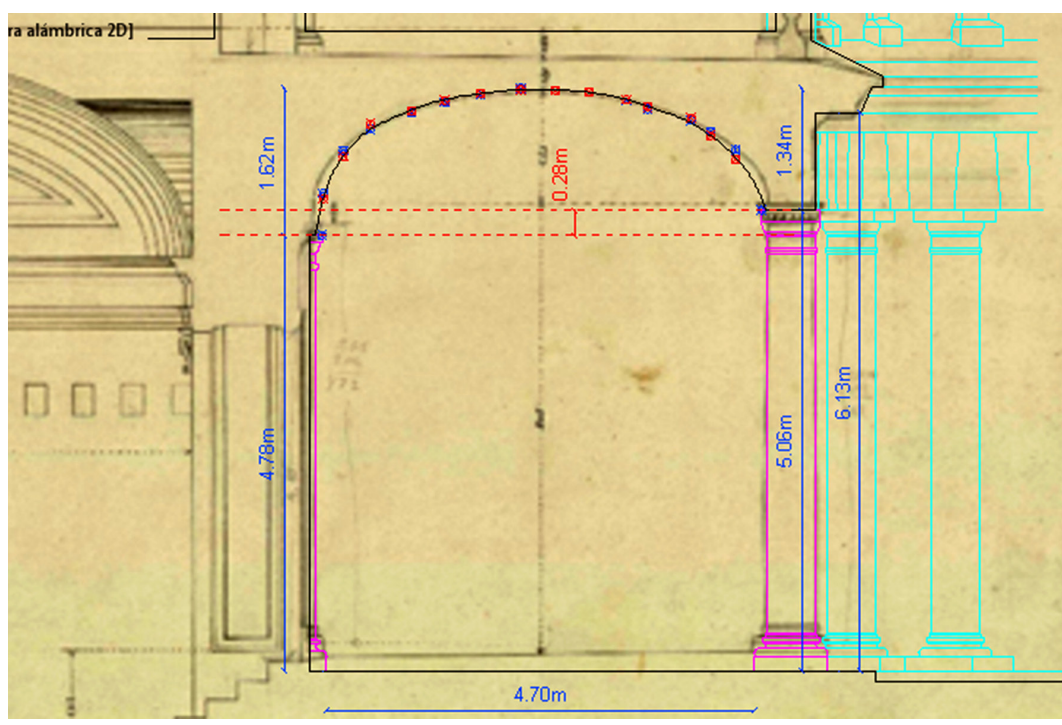

Figura 12. Superposición (en rojo) de las mediciones realizadas sobre una sección sacada de los archivos del Patronato de la Alhambra en la que puede observarse la asimetría del arco carpanel por tranquil en favor de un perfil que dirige la resultante de los esfuerzos al anillo formado por el arco plano. (Elaboración propia). 


\section{CONCLUSIONES}

Se hace visible el conocimiento profundo por parte del tracista del comportamiento mecánico de la bóveda toroidal, de la geometría y sistemas de representación gráficos, de la maestría en las trazas y corte de cantería y de la consecuente puesta en obra. Circunstancia que, sumada al conjunto de referencias en la traza del palacio cristiano a los palacios nazaríes (tanto al Palacio de Comares como al Palacio de los Leones, que no han sido expuestas en este texto) y a su delicada inserción compositiva, invita a reivindicar la autoría del proyecto en un arquitecto conocedor del conjunto alhambreño, que bien pudiera ser Pedro Machuca, a pesar de lo tentadora que pueda seguir resultando la atribución italiana.

De esta forma, Machuca igualaría en prestigio a alguno de sus contemporáneos como Siloé, tanto en el ejercicio proyectual como en la ejecución de una de las mejores bóvedas toroidales de cantería del Renacimiento Español.

Creemos que la solución constructiva descrita:

Explica la posible ejecución de la bóveda, con una optimización de recursos y medios auxiliares.

Posibilita su perfecta definición geométrica, ya que el sistema de apeo, mediante los codales y las cerchas horizontales dispuestas sobre los ábacos de las columnas y pilastras, facilita el giro de la cimbra sin que se produzca ningún tipo de deformación.

Con esta aportación, creemos que contribuimos a la ampliación del conocimiento en el campo de la Historia de la Construcción.

\section{REFERENCIAS}

(1) López, R. (1992) El Renacimiento en Granada. Cuadernos de Arte Español. Historia 16. 18: p. 18.

(2) Tafuri, M. (1995). Sobre el Renacimiento. Principios, Ciudades, Arquitectos. pp.226. Madrid: Cátedra.

(3) Henares, I. (1992) Arquitectura y Mecenazgo; ideal aristocrático, reforma religiosa y utopía política en el renacimiento andaluz. En AA.VV. La arquitectura del Renacimiento en Andalucía. Andrés de Vandelvira y su época. (p. 6o). Sevilla: Consejería de Cultura y Medio Ambiente de la Junta de Andalucía.

(4) Rosenthal, E. (1988). El Palacio de Carlos V de Granada, p. 169. Madrid: Alianza Editorial S.A.

(5) Tafuri, M. (1987). El Palacio de Carlos V en Granada: arquitectura ‘a lo romano’ e iconografía imperial. Cuadernos de la Alhambra, (24): 77-108.

(6) Tafuri, M. (1995). Sobre el Renacimiento. Principios, Ciudades, Arquitectos. p. 242. Madrid: Cátedra.

(7) Rodriguez, D. (2000). Sobre los dibujos del Palacio de Carlos V en la Alhambra de Granada conservados en la Real Biblioteca. Reales Sitios: Revista del Patrimonio Nacional. (145): 16-27.

(8) Tafuri, M. (1995). Sobre el Renacimiento. Principios, Ciudades, Arquitectos. pp.253-264. Madrid: Cátedra.

(9) Capitel, A. (1992). Metamorfosis de monumentos y teorías de la restauración. pp. 89-109. Madrid: Alianza Editorial, S.A.

(10) Galera, P. (2000). Carlos Vy la Alhambra. Fichas 1, 2 y 3, pp. 197-202. Granada: Patronato de la Alhambra. Consejería de Cultura - Talleres Gráficos Arte.

(11) Galera, P. (1995). El Palacio de Carlos V: La idea arquitectónica. En Rodriguez, J. P. (Coord.) El Palacio de Carlos V: Un siglo para la recuperación de un monumento, (p. 27). Granada: Comares.

(12) Galera, P. (2000). Carlos Vy la Alhambra. Fichas 1, 2 y 3, pp. 227-229. Granada: Patronato de la Alhambra. Consejería de Cultura - Talleres Gráficos Arte.

(13) Galera, P. (2000). Carlos Vy la Alhambra. Fichas 1, 2 y 3, pp. 213-214. Granada: Patronato de la Alhambra. Consejería de Cultura - Talleres Gráficos Arte.

(14) Chueca, F. (2001). Edad Moderna y Contemporánea. En Historia de la Arquitectura Española, Tomo II (p. 115). Ávila: Diputación Provincial.

(15) Galera, P. (1995). El Palacio de Carlos V: La idea arquitectónica. En Rodriguez, J. P. (Coord.) El Palacio de Carlos V: Un siglo para la recuperación de un monumento, (p. 29). Granada: Comares.

(16) Calvo, J., Alonso, M.A. (2010). Perspective versus Stereotomy: From Quattrocento Polyhedral Rings to Sixteenth-Century Spanish Torus Vaults. Nexus Network Journal, 12(1): 75-111, doi: http://dx.doi.org/10.1007/s00004-010-0018-4.

(17) Rosenthal, E. (1988). El Palacio de Carlos V de Granada, p. 42. Madrid: Alianza Editorial S.A.

(18) Rosenthal, E. (1988). El Palacio de Carlos V de Granada, p. 119. Madrid: Alianza Editorial S.A.

(19) Palacios, J. C. (1990). Trazas y cortes de Cantería en el Renacimiento Español, pp. 255-261. Madrid: Ministerio de Cultura, Dirección General de Bellas Artes y Archivos - Instituto de Conservación y Restauración de Bienes Culturales.

(20) Fotografías realizadas por D. José García Ayola. (1863-1900). Granada: Patronato de la Alhambra y Generalife. Servicio de Investigación y Difusión. Departamento de Archivo y Biblioteca. 